\title{
Optimización de la Concentración de L-Cisteína para la producción de 1,3-Propanodiol por una vía Biotecnológica
}

\author{
Tatiana F. Ferreira, Roberta dos R. Ribeiro, Pedro M. Matos y Maria Alice Z. Coelho \\ Universidade Federal do Rio de Janeiro, Departamento de Engenharia Bioquímica, Escola de Química, \\ C.P. 68542, Rio de Janeiro-Brasil (e-mail: tatianafelix@ufrj.br)
}

Recibido Jul. 04, 2012; Aceptado Ago. 21, 2012; Versión final recibida Oct. 20, 2012

\begin{abstract}
Resumen
Se ha realizado la conversión de glicerol en 1,3-propanodiol (1,3-PDO) usando la cepa Citrobacter freundii ATCC 8090. El 1,3-PDO es una molécula bifuncional que puede ser utilizada para muchas aplicaciones, siendo así de gran interés comercial. Una ruta más reciente para la producción de este compuesto es la vía biotecnológica utilizando algunos microorganismos capaces de convertir anaeróbicamente glicerol en 1,3-PDO. La conversión realizada hace necesaria la adición de cisteína al medio de cultivo. Se realizaron cinco experimentos con cinco concentraciones de cisteína con el fin de verificar cuál es la menor concentración posible que no afecta la conversión de glicerol en 1,3-PDO. Las concentraciones utilizadas fueron 0,$05 ; 0,10 ; 0,15 ; 0,20$ y $0,25 \mathrm{~g} \cdot \mathrm{L}^{-1}$. Los rendimientos fueron $15,20,26,35$ y $28 \%$ respectivamente. De acuerdo a los resultados se concluye que la concentración óptima de cisteína para la producción de 1,3-PDO es $0,20 \mathrm{~g} \cdot \mathrm{L}^{-1}$.
\end{abstract}

Palabras clave: 1,3-propanodiol, 1,3-PDO, Citrobacter freundii, cisteína, glicerol

\section{Optimization of L-Cysteine Concentration to produce 1,3-Propanediol by a Biotechnological route}

\begin{abstract}
Glycerol was converted into 1,3-propanediol (1,3-PDO) using Citrobacter freundii ATCC 8090. 1,3-PDO is a bifunctional molecule that can be used in many applications, being of great commercial interest. The most recent route used for the production of this compound is through biotechnology using some microorganisms capable of anaerobically converting glycerol into 1,3-PDO. The conversion done makes it necessary the addition of cysteine to the culture medium. Five experiments were performed with cysteine at five concentrations to verify which is the optimum concentration that does not affect conversion of glycerol into 1,3-PDO. The concentrations used were $0.05,0.10,0.15,0.20$ and $0.25 \mathrm{gL}^{-1}$. The yields were 15,20 , 26,35 and $28 \%$ respectively. According to the results it is concluded that the optimum cysteine concentration for 1,3-PDO production is $0.20 \mathrm{~g} \cdot \mathrm{L}^{-1}$.
\end{abstract}




\section{INTRODUCCIÓN}

El propan-1,3-diol, también conocido como trimetilenoglicol o 1,3-di-hidroxipropano, es un diol con tres átomos de carbono en su estructura. Por ser una molécula orgánica bifuncional, el 1,3-propanodiol (1,3PDO) tiene varias propiedades promisorias para reacciones de síntesis, especialmente como monómero para la producción de poliésteres, poliéteres y poliuretanos (Zeng y Biebl, 2002). El 1,3-PDO posee también una serie de otras aplicaciones interesantes, como por ejemplo, aditivos para solvente (mejora de propiedades), adhesivos, laminados, resinas (viscosidad intrínseca baja, menos solvente para el revestimiento), detergentes (prevenir separación de fases y pérdida de actividad enzimática) y cosméticos (de larga duración y residuos no adherentes) (Barbirato et al., 1998). El compuesto 1,3-PDO puede ser producido por vía química o biotecnológica. La vía biotecnológica utiliza glicerol como sustrato. La producción microbiana de 1,3-PDO a partir de glicerol se ha demostrado principalmente por Klebsiella pneumoniae, Citrobacter freundii, Clostridium pasteurianum y Clostridium butyricum (Anand et al., 2011). Este monómero ha sido tradicionalmente considerado como una especialidad química. Sin embargo, ahora está experimentando una transición hacia una commodity química (Saxena et al. 2009).

La producción de biodiesel genera glicerol como subproducto. Se estima que por cada kilogramo producido de biodiesel se generan aproximadamente 0,1 kilogramos de glicerol. Debido a que se proyecta un aumento en la demanda de biodiesel, el aprovechamiento de la glicerina se convierte pues en un tema de suma importancia, puesto que con ello se mejora notablemente la economía global del proceso de producción de biodiesel (Cardeño et al., 2011). Por lo tanto, muchos procesos han ganado importancia con el fin de tomar ventaja de lo glicerol de la producción de biodiesel. En este estudio la conversión de glicerol a 1,3-PDO se realizó mediante el uso de una cepa C. freundii. En este trabajo fue utilizada una cepa de Citrobacter freundii. Citrobacter es un género de bacterias gran-negativas de la familia Enterobacteriaceae. C. freundii es una bacteria anaerobia facultativa con una amplia tolerancia al oxígeno, que se encuentra ampliamente en el agua, el suelo, los alimentos y el tracto intestinal de animales y seres humanos (Yang et al., 2011).

El glicerol es convertido en 1,3-PDO por vía biotecnológica a través de dos etapas. En la primera etapa, la enzima glicerol deshidratasa cataliza la remoción de una molécula de agua del glicerol, produciendo 3hidroxipropionaldeído (3-HPA). En la segunda etapa, la enzima 1,3-propanodiol oxidorreductase reduce el 3-HPA a 1,3-PDO simultáneamente a la oxidación de la forma reducida del cofactor nicotinamida adenina dinucleótideo (NADH) para su forma oxidada, $\mathrm{NAD}^{+}$(Nakamura y Whitedy, 2003). La enzima glicerol deshidratase, que cataliza el primer paso de la producción de 1,3-PDO, actúa a través de un mecanismo que implica la coenzima $B_{12}$ como un cofactor esencial (Knietsch et al., 2003). Para la síntesis de coenzima $B_{12}$ (adenosilcobalamina) es entonces necesario añadir cobalto al medio de cultivo (Toraya, 2000).

Los estudios que implican la producción de 1,3-PDO a partir de glicerol por $C$. freundii se realizaron en medio de cultivo que contiene L-cisteína como agente reductor (Boeingk et al. 1993). Muchos otros estudios con fermentación anaeróbica en la literatura también utilizaron L-cisteína como agente reductor (Xie et al., 2008, Li et al. 2008). En la producción biotecnológica de 1,3-PDO, la segunda etapa enzimática es NADH dependiente y genera la especie oxidada $N A D^{+}$. Por lo tanto, la regeneración de $N A D H$ es necesaria para producir 1,3-PDO. La cisteína actúa como agente reductor, siendo responsable por la reducción de $\mathrm{NAD}^{+}$a NADH. El mecanismo de acción de la cisteína implica la liberación de gas $\mathrm{H}_{2} \mathrm{~S}$, que genera un ligero olor a huevos podridos (Zhao et al., 2011). Sin embargo, la cisteína es una materia-prima de elevado costo que debe ser utilizada en la menor concentración posible. El objetivo del presente trabajo fue realizar la producción de 1,3-PDO a partir de glicerol utilizando la cepa Citrobacter freundii ATCC 8090 en diferentes concentraciones de cisteína a fin de buscar la menor concentración posible de este aminoácido que no afecte el rendimiento del proceso.

\section{MATERIALES Y MÉTODOS}

Los componentes de los medios de cultivo que fueron utilizados son: extracto de levadura (Oxoid Hampshire, UK), glicerol (Vetec - Rio de Janeiro, BR) y L-cisteína (Sigma - St. Louis, MO). Fue utilizado también un medio de cultivo formulado industrialmente, LB Broth Base (Invitrogen - Carlsbad, CA). La bacteria utilizada en el presente trabajo fue Citrobacter freundii ATCC 8090.

\section{Condiciones de cultivo}

Las células fueron estocadas en medio semisólido a $4^{\circ} \mathrm{C}$. Para la proliferación celular, células del medio de almacenamiento fueron inoculadas en condiciones anaeróbicas en Erlenmeyer de $1000 \mathrm{~mL}$ conteniendo $400 \mathrm{~mL}$ de Meio LB $2 \%$ e incubadas a $30^{\circ} \mathrm{C}$ en un agitador rotatorio e manteniendo 250 oscilaciones/min. Después de 8 horas, las células fueron centrifugadas y suspendidas en el medio de cultivo. 


\section{Experimentos}

Los experimentos fueron realizados en condiciones anaerobias en Erlenmeyer de $500 \mathrm{~mL}$ con $200 \mathrm{~mL}$ de medio líquido a $30^{\circ} \mathrm{C}$ en incubadora rotativa (shaker) con agitación de 250 rpm e inóculo de aproximadamente $1,0 \mathrm{mg} \cdot \mathrm{mL}^{-1}$ de células. Estos experimentos fueron realizados por 48 horas con muestreos para análisis de crecimiento celular, medida de $\mathrm{pH}$, consumo de glicerol, producción de 1,3-PDO y co-productos. El medio de cultivo utilizado fue adaptado de Barbirato et al. (1998) y se encuentra descrito en la Tabla 1.

Tabla 1: Medio de cultivo utilizado en el experimento con Citrobacter freundii ATCC8090.

\begin{tabular}{l}
\hline Citrobacter freundii \\
\hline $20 \mathrm{~g} \cdot \mathrm{L}^{-1}$ glicerol \\
$14 \mathrm{~g} \cdot \mathrm{L}^{-1} \mathrm{~K}_{2} \mathrm{HPO}_{4}$ \\
$6 \mathrm{~g} \cdot \mathrm{L}^{-1} \mathrm{KH}_{2} \mathrm{PO}_{4}$ \\
$3 \mathrm{~g} \cdot \mathrm{L}^{-1}\left(\mathrm{NH}_{4}\right)_{2} \mathrm{SO}_{4}$ \\
$0,2 \mathrm{~g} \cdot \mathrm{L}^{-1} \mathrm{MgSO}_{4} \cdot 7 \mathrm{H}_{2} \mathrm{O}$ \\
$0,012 \mathrm{~g} \cdot \mathrm{L}^{-1} \mathrm{CoCl}_{2} \cdot 6 \mathrm{H}_{2} \mathrm{O}$ \\
$0,2 \mathrm{~g} \cdot \mathrm{L}^{-1}$ extracto de levadura \\
$\mathrm{pH}=7,0$
\end{tabular}

\section{Métodos Analíticos}

Cuantificación celular: La concentración celular fue medida a través de la densidad óptica a $580 \mathrm{~nm}$ y estos valores fueron convertidos para $\mathrm{mg}$ de peso seco de células/ $\mathrm{mL}$ utilizándose el factor de conversión obtenido por la curva de peso seco.

Cuantificación de 1,3-propanodiol y co-produtos: Los análisis para cuantificar la producción de 1,3-PDO y algunos posibles co-produtos como 2,3-butanodiol, etanol y los ácidos oxálico, succínico, cítrico, pirúvico, láctico y acético fueron realizados por Cromatografía Líquida de Alta Eficiencia (Waters ${ }^{\circledR}$ ). Para la realización de tales análisis se utilizó una columna Aminex® HPX- 87H, 300 x 7,8mm (Bio-Rad Laboratories Ltd) acoplada a una precolumna de intercambio catiónico (Bio-Rad Laboratories Ltd), detector de IR (Waters 2414), bomba binaria (Waters 1525), horno y módulo controlador de temperatura (Waters), software cromatográfico: Breeze. La fase móvil utilizada fue $\mathrm{H}_{2} \mathrm{SO}_{4} 5 \mathrm{mM}$ con flujo de $0,8 \mathrm{~mL} / \mathrm{min}$, el volumen de inyección fue $20 \mu \mathrm{L}$ y la temperatura de corrida fue $60^{\circ} \mathrm{C}$.

Cuantificación del consumo de glicerol: Los análisis para cuantificar el consumo de glicerol también fueron realizados por Cromatografía Líquida de Alta Eficiencia (Waters ${ }^{\circledR}$ ). La metodología utilizada fue la misma descrita anteriormente.

Análisis de $\mathrm{pH}$ : El pH de los medios de cultivos fue analizado en un pHmetro Digimed modelo Digimed DM22

\section{RESULTADOS Y DISCUSIÓN}

Fueron realizados cinco experimentos con diferentes concentraciones iniciales de L-cisteína en el medio de cultivo. Las concentraciones de L-cisteína utilizadas, así como la concentración final de 1,3-PDO producido, el rendimiento en este producto de interés y el pH final se encuentran en la Tabla 2. En la Tabla, los valores de concentración de L-cisteína y producción de 1,3-PDO se encuentran en $\mathrm{g} \cdot \mathrm{L}^{-1}$ y el rendimiento se encuentra en \%.

Tabla 2: Concentración de L-cisteína utilizada, producción de 1,3-PDO, rendimiento en 1,3PDO y pH final de los diferentes experimentos con Citrobacter freundii ATCC8090.

\begin{tabular}{ccccc}
\hline Medio & [L-cisteína] $^{*}$ & Producción de 1,3-PDO* $^{*}$ & Rendimiento $^{(Y \mathrm{p} / \mathrm{s})^{*}}$ & $\mathrm{pH}_{\text {final }}$ \\
\hline 1 & 0,05 & 1,46 & 15 & 6,38 \\
2 & 0,10 & 2,23 & 20 & 6,63 \\
3 & 0,15 & 3,25 & 26 & 6,33 \\
4 & 0,20 & 3,90 & 35 & 6,65 \\
5 & 0,25 & 4,81 & 28 & 6,31 \\
\hline
\end{tabular}


En el Medio 1, no hubo crecimiento microbiano. Sin embargo, ocurrió consumo de aproximadamente la mitad del glicerol y la producción de 1,3-PDO alcanzó 1,46 g..-1, con un rendimiento (Yp/s) del $15 \%$. Entre los co-productos analizados, el ácido acético fue el único detectado, alcanzando $1,63 \mathrm{~g} \cdot \mathrm{L}^{-1}$, con un pH final de 6,38. Las curvas de crecimiento celular, consumo de glicerol y producción de 1,3-PDO y ácido acético en el Medio 1 están representadas en la Figura 1. Vale destacar que este rendimiento fue obtenido con 17 horas de experimento donde el consumo de glicerol y la producción de 1,3-PDO habían parado.

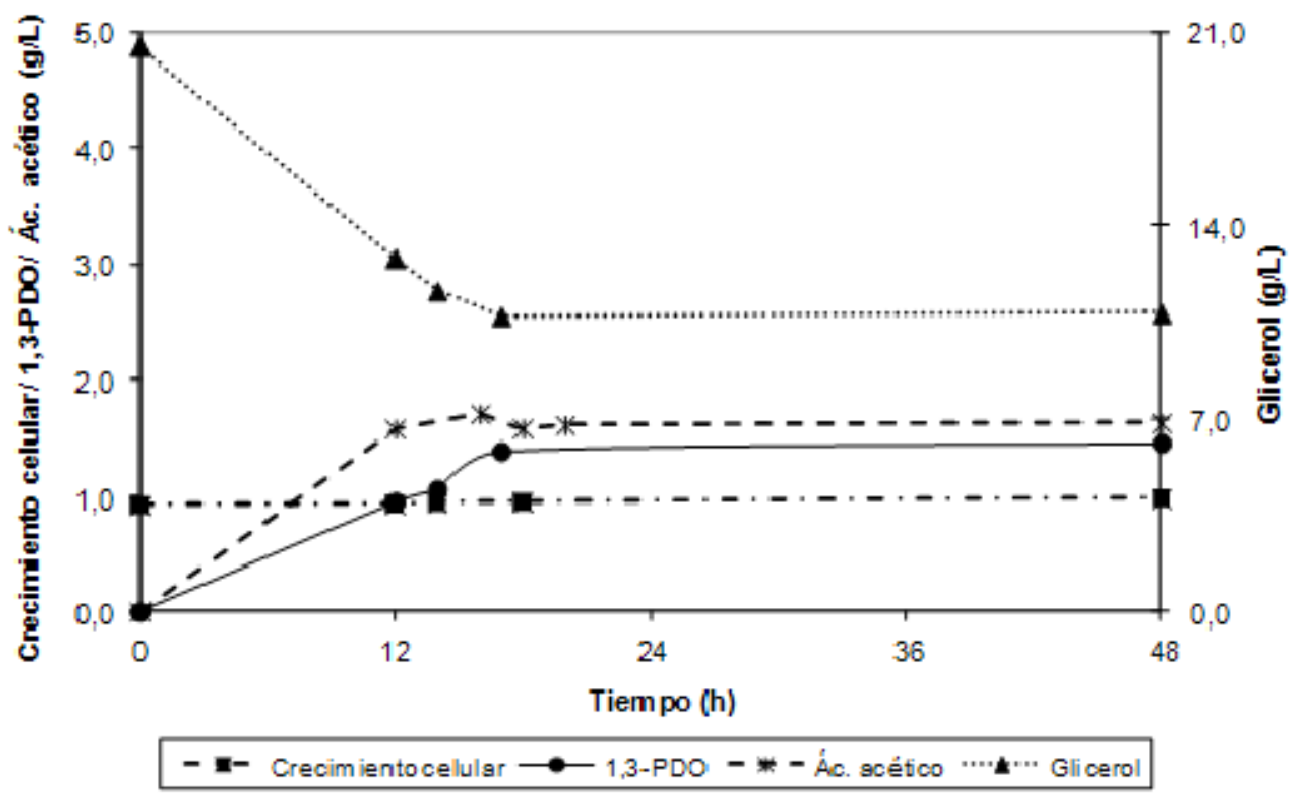

Fig. 1: Crecimiento celular, consumo de glicerol y producción de 1,3- PDO y ácido acético en el Medio 1.

En el Medio 2, tampoco hubo crecimiento microbiano, aunque el consumo de glicerol y la producción de 1,3-PDO hayan sido un poco superiores al obtenido en el Medio 1, resultando en un rendimiento ( $\mathrm{Yp} / \mathrm{s})$ de $20 \%$. Así como en el Medio 1, el único co-producto formado fue el ácido acético en concentración de 1,05 g. $\mathrm{L}^{-1}$ y con $\mathrm{pH}$ final de 6,63. Las curvas de crecimiento celular, consumo de glicerol y producción de 1,3PDO y ácido acético en el Medio 2 están representadas en la Figura 2. Es posible verificar que ni el consumo de glicerol ni la producción de 1,3-PDO pararon con 17 horas de experimento como ocurrió en el Medio 1.

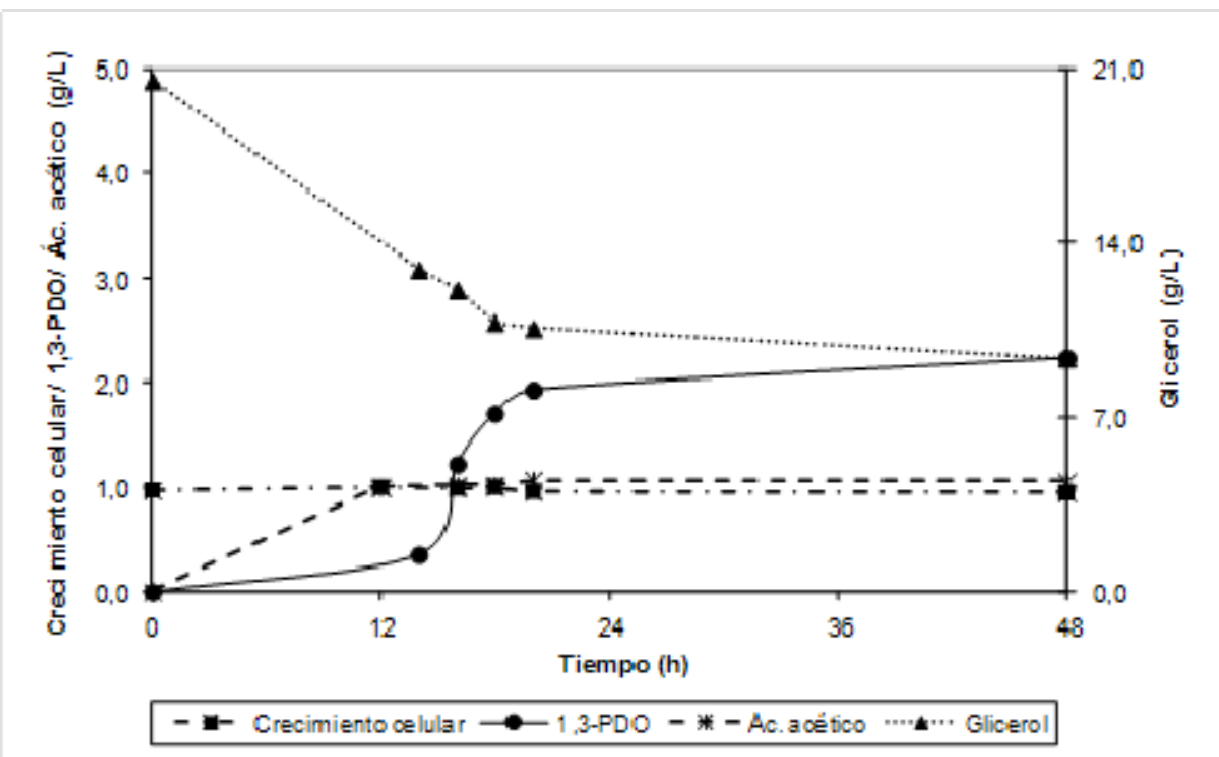

Fig. 2: Crecimiento celular, consumo de glicerol y producción de 1,3-PDO y ácido acético en el Medio 2. 
En el Medio 3, el crecimiento microbiano no fue expresivo, fue consumida más de la mitad del glicerol y la producción de 1,3-PDO alcanzó $3,25 \mathrm{~g} \cdot \mathrm{L}^{-1}$, generando un rendimiento $(\mathrm{Yp} / \mathrm{s})$ del $26 \%$. Hubo producción de $1,80 \mathrm{~g} \cdot \mathrm{L}^{-1}$ de ácido acético y el $\mathrm{pH}$ final fue 6,33 . Las curvas de crecimiento celular, consumo de glicerol y producción de 1,3-PDO y ácido acético en el Medio 3 se encuentran en la Figura 3.

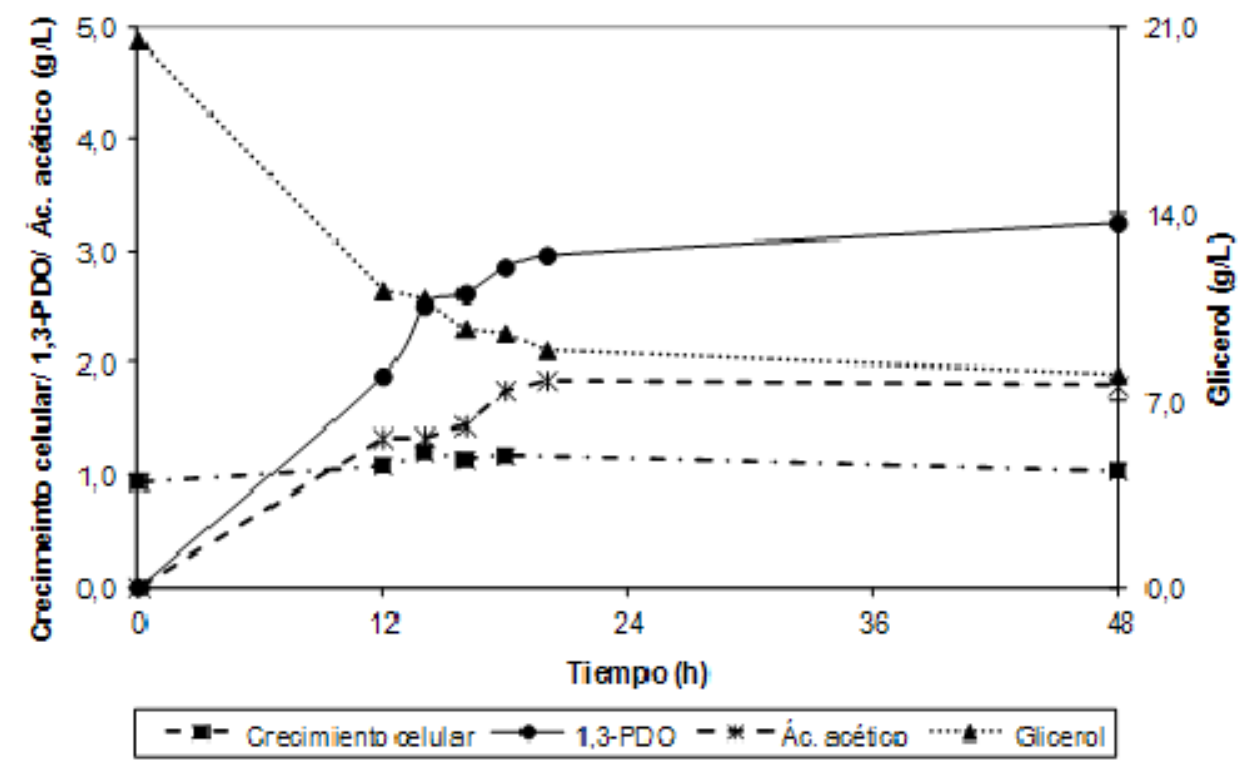

Fig. 3: Crecimiento celular, consumo de glicerol y producción de 1,3-PDO y ácido acético en el Medio 3.

En el Medio 4, hubo crecimiento microbiano, el consumo de glicerol fue expresivo y la producción de 1,3PDO alcanzó 3,90 g. $\mathrm{L}^{-1}$, con un rendimiento $(\mathrm{Yp} / \mathrm{s})$ del $35 \%$. La producción de ácido acético alcanzó 1,95 g. $\mathrm{L}^{-1}$ y el $\mathrm{pH}$ final fue 6,65 . Las curvas de crecimiento celular, consumo de glicerol y producción de 1,3-PDO y ácido acético en el Medio 4 se encuentran en la Figura 4.

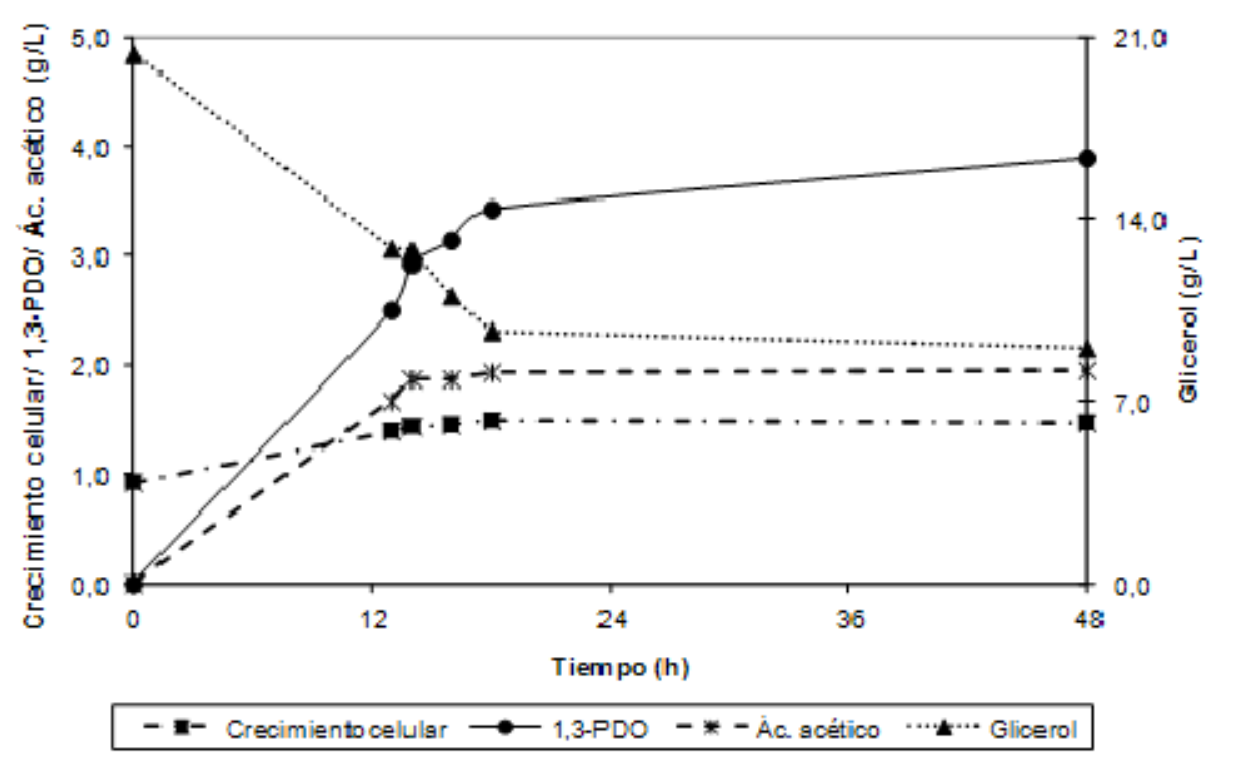

Fig. 4: Crecimiento celular, consumo de glicerol y producción de 1,3-PDO y ácido acético en el Medio 4.

Estos resultados indican que el Medio 4, donde la concentración de cisteína fue $0,20 \mathrm{~g} \cdot \mathrm{L}^{-1}$, fue el de mejor condición para la transformación de glicerol en 1,3-PDO. Además de esta concentración hubo una reducción en el rendimiento del producto de interés como muestra la Tabla 3. Siendo así, algunos parámetros necesitan ser estudiados con el fin de favorecer la vía de producción 1,3-PDO en detrimento de la vía de producción de ácido acético. Sin embargo, un punto importante a tratar es la sustitución de Lcisteína por un residuo que contiene este aminoácido en la concentración cerca del ideal para la producción de 1,3-PDO, lo que reduciría los costes de producción de este monómero. 
Tabla 3: Rendimientos en 1,3-PDO, ácido acético y biomasa de los experimentos realizados. Los valores de rendimiento se encuentran en $\%$.

\begin{tabular}{cccccc}
\hline Medio & [Cisteína] $\left(\mathrm{g} \cdot \mathrm{L}^{-1}\right)$ & $\mathrm{Yp}^{-} \mathrm{s}_{1,3-\mathrm{PDO}^{*}}$ & $\mathrm{Yp}_{\mathrm{s}}$ Ac. acético $^{*}$ & $\mathrm{YX} / \mathrm{s}^{*}$ & Total \\
\hline 1 & 0,05 & 15 & 17 & $<1$ & 32 \\
2 & 0,10 & 20 & 9 & $<1$ & 29 \\
3 & 0,15 & 26 & 14 & 2 & 42 \\
4 & 0,20 & 35 & 32 & 4 & 71 \\
5 & 0,25 & 28 & 11 & 7 & 46 \\
\hline
\end{tabular}

El Medio 5 también presentó un expresivo crecimiento celular y la producción de 1,3-PDO alcanzó 4,8 g.:-1. No obstante, el consumo de glicerol fue bien elevado, resultando en un rendimiento de 1,3-PDO (Yp/s) del $28 \%$, inferior al rendimiento (Yp/s) obtenido en el Medio 4. La producción de ácido acético fue 1,88 g. ${ }^{-1}$ y el pH final fue 6,31. Las curvas de crecimiento celular, consumo de glicerol y producción de 1,3-PDO y ácido acético en el Medio 5 se encuentran en la Figura 5.

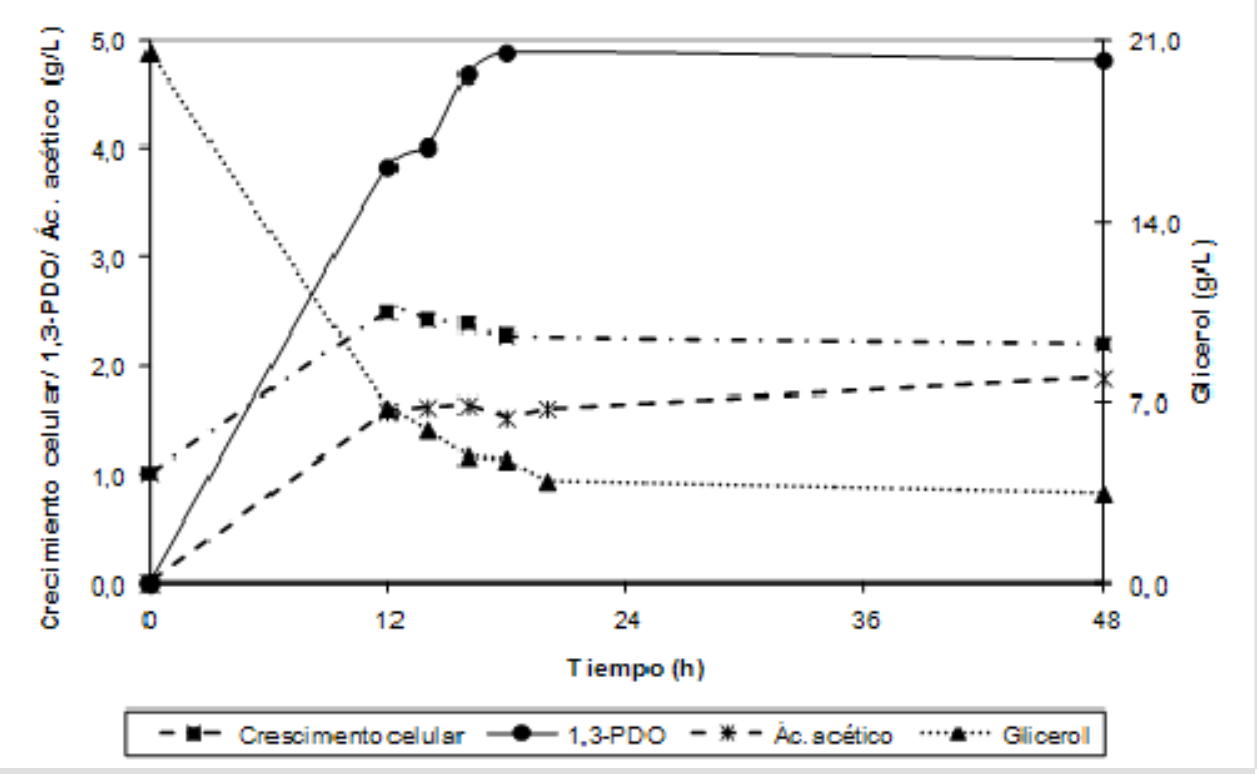

Fig. 5: Crecimiento celular, consumo de glicerol y producción de 1,3-PDO y ácido acético en el Medio 5.

El ácido acético es el único compuesto producido por Citrobacter freundii que no utiliza NADH en su vía de producción, proporcionando así, mayor cantidad de NADH para la producción de 1,3-PDO (Biebl et al., 1999). Esto explica el hecho de que el experimento en el Medio 4 haya presentado mayor rendimiento en 1,3-PDO, visto que este presentó también mayor rendimiento en ácido acético. Posiblemente, en los otros experimentos hubo mayor producción de algún co-producto que utiliza NADH en su vía de producción como, por ejemplo, $\mathrm{CO}_{2}$.

Por el hecho de haber bajado $\mathrm{p} K_{a}$ la cisteína se oxida de forma selectiva (Rhee et al., 2000). Así, la cisteína reduce $\mathrm{NADH}$ a NADH. $\mathrm{H}^{+}$, aumentando la disponibilidad de la forma reducida NADH. $\mathrm{H}^{+}$. El mecanismo de acción de la cisteína implica en la liberación de gas $\mathrm{H}_{2} \mathrm{~S}$, que genera un ligero olor a huevos podridos (Zhao et al., 2011), que se observó en todos los experimentos.Sin embargo, este aminoácido no es un agente de reducción barata.

Las corrientes catalíticas y el potencial de oxidación para cisteína son dependientes del pH de la solución, el potencial es menos positivo a medida que aumenta el $\mathrm{pH}$ y las corrientes catalíticos decrecientes con el aumento en el pH, para la misma concentración de cisteína (Maree y Nyokong, 2000). Esta es una razón que muestra la necesidad de controlar el pH durante la producción de 1,3-PDO.

\section{CONCLUSIONES}

En los Medios 1, 2 y 3, la concentración de L-cisteína no fue suficiente para promover el crecimiento celular utilizando glicerol como fuente de carbono. Sin embargo, hubo producción de 1,3-PDO y ácido acético. En los Medios 4 e 5, ocurrió crecimiento celular y una elevada producción de 1,3-PDO y ácido acético. El 
mayor rendimiento de 1,3-PDO y ácido acético fue obtenido en el Medio 4. Estos resultados indican que el Medio 4, donde la concentración de cisteína fue $0,20 \mathrm{~g} \cdot \mathrm{L}^{-1}$, fue el de mejor condición para la transformación de glicerol en 1,3-PDO. Un punto importante a tratar es la sustitución de L-cisteína por un residuo que contiene este aminoácido en la concentración cerca del ideal para la producción de 1,3-PDO, lo que reduciría los costes de producción de este monómero.

\section{AGRADECIMIENTOS}

Los autores agradecen a PETROBRAS, CNPq y FAPERJ, el apoyo financiero.

\section{REFERENCIAS}

Anand P., R.K. Saxena y R.G. Marwah, A novel downstream process for 1,3-propanediol from glycerolbased fermentation, Appl Microbiol Biotechnol, 90, 1267-1276 (2011).

Barbirato F., E.H. Himmi, T. Conte y A. Bories, 1,3-propanediol production by fermentation: an interesting way to valorize glycerin from the ester and ethanol industries, Ind. Crops and Products, 7, 281-289 (1998).

Biebl H., K Menzel., A.-P. Zeng y W.-D. Deckwer, Microbial production of 1,3-propanediol, Appl Microbiol Biotechnol, 52, 289-297 (1999).

Boeingk R., S. Bowien, G. Gottshchalk, Fermentation of glycerol to 1,3-propanediol in continuous cultures of Citrobacter freundii. Appl Microbiol Biotechnol, 38, 453-457 (1993).

Cardeño F., L. J. Gallego y L. A. Rios, Refinación de la Fase Glicerina del Biodiesel de Aceite de Palma empleando Ácidos Minerales, Información Tecnológica, 22(6), 15-24 (2011).

Knietsch A., S. Bowien, G. Whited, G.Gottschalk y R.Daniel, Identification and Characterization of Coenzyme B12-Dependent Glycerol Dehydratase- and Diol Dehydratase-Encoding Genesfrom Metagenomic DNA Libraries Derived from Enrichment Cultures. Applied and Environmental Microbiology, 69(6), 3048-3060 (2003).

Maree S. y T. Nyokong, Electrocatalytic behavior of substituted cobalt phthalocyanines towards the oxidation of cysteine. Journal of Electroanalytical Chemistry, 492(2), 120-127 (2000).

Nakamura C. E. y G. M. Whited, Metabolic engineering for the microbial production of 1,3-propanediol, Current Opinion in Biotechnology, 14, 454-459 (2003).

Rhee S.G., Y.S. Bae, S.-R. Lee y J. Kwon, Hydrogen Peroxide: A Key Messenger That Modulates Protein Phosphorylation Through Cysteine Oxidation, Sci. STKE, 2000(53), pe1 (2000).

Saxena R.K., P. Anand, S. Saran y J. Isar, Microbial production of 1,3-propanediol: Recent developments and emerging opportunities, Biotechnology Advances, 27, 895-913 (2009).

Toraya T., Radical catalysis of $\mathrm{B}_{12}$ enzymes: structure, mechanism, inactivation, and reactivation of diol and glycerol dehydratases. Cell. Mol. Life Sci., 57, 106-127, (2000).

Yang C., P. Jiang, S. Xiao, C. Zhang, K. Lou y X.-H. Xing, Fed-batch fermentation of recombinant Citrobacter freundii with expression of a violacein-synthesizing gene cluster for efficient violacein production from glycerol. Biochemical Engineering Journal, 57, 55-62 (2011).

Zeng A. P. y H. Biebl, Bulk chemicals from biotechnology: the case of 1,3-propanediol production and the new trends. Advances in biochemical engineering/ biotechnology, 74, 239-259 (2002). 
